\title{
Diálogos sobre Raça e Saúde na América Latina
}

OSMUNDO PINHO

\author{
MONTEIRO, Simone; SANSONE, Livio (Org.) \\ Etnicidade na América Latina: \\ um debate sobre raça, saúde e direitos reprodutivos \\ Rio de Janeiro: FIOCRUZ. 2004. 344p.
}

O contencioso sobre as representações e práticas adequadas sobre raça, racismo e suas inter-relações com diversos campos da reflexão e da ação tem adquirido crescente volume, complexidade e abrangência na sociedade brasileira. É resultado provável da profunda e extensa desigualdade racial e da opressão étnica que atinge povos indígenas, mas também da democratização da sociedade brasileira, de seu dinamismo, de novas conexões com as correntes globais de afirmação de direitos e com as políticas transnacionais de identidade e reconhecimento.

O processo é delicado e não poderia se desenrolar sem provocar alguma tensão, embaraço ou desconforto. Cultivamos durante décadas uma autoimagem complacente como nação "cordial", onde prevalecia o "preconceito de ter preconceito". Um país no qual não havia nenhum problema racial e onde a miscigenação, fórmula mágica conjurada por feiticeiros de ontem e de hoje, impedia o racismo. Ora, essa auto-imagem ruiu, ou está ruindo, com maior ou menor estrondo. A Universidade brasileira, e em particular as Ciências Sociais, tem à sua frente o desafio de se abrir para as transformações sociais e incorporálas, ao tempo em que medita sobre elas, em que fornece elementos críticos e analíticos para compreendê-las, para identificar melhor seu próprio papel institucional nesse contexto.

Não poderíamos, de outro modo então, senão saudar com entusiasmo a publicação do volume ora resenhado. Etnicidade na América Latina: um debate sobre raça, saúde e direitos reprodutivos é a publicação resultante do seminário "Raça / Etnicidade na América Latina: questões sobre saúde e direitos reprodutivos", realizado na cidade do Rio de Janeiro, em novembro de 2001. O evento foi organizado pelo Laboratório de Educação em Ambiente e 
Saúde do Departamento de Biologia, do Instituto Oswaldo Cruz, e contou com apoio da Fundação Ford. O seminário, amplamente representativo da reflexão nacional sobre o tema, contou com a participação de diversas instituições brasileiras, assim como representou um momento de diálogo importante com pesquisadores de outros países da América Latina, a exemplo da Colômbia.

Além de permitir um balanço importante da produção acadêmica na área, o seminário também produziu um encontro memorável entre a universidade e diferentes setores da sociedade civil organizada, notadamente de organizações negras, como o Fala Preta e o Afroreggae; feministas, como a CEPIA(Cidadania Estudo Pesquisa Informação e Ação), além de organizações latino-americanas, como o Grupo de Estudios sobre la Mujer, do México.

A riqueza e a densidade produzidas por esse encontro refletem bem o ambiente fecundo e por vezes tensionado em que os debates se desenvolvem. Nas palavras dos próprios organizadores:

"Embora nem sempre fácil, compreende-se que a interlocucão entre pesquisadores, militantes e pesquisadores-ativistas deve ser fomentada. A leitura dos artigos permite a identificação da riqueza, das dificuldades e do potencial de interação entre esses atores sociais para a produção de conhecimento e para a formulação de políticas públicas” (p. 9).

O livro está dividido em quatro partes. Na primeira, "Perspectivas histórica e contemporânea", entramos em contato com um amplo panorama, com profundidade histórica, teórica e regional. No artigo de Marcos Chor Maio, "Raça, doença e saúde pública no Brasil", o autor polemiza com o historiador S. Chaloub, ao argumentar que os "intelectuais-médicos" da República Velha não tinham um projeto eugênico ou racial submetido aos interesses do Capital, como argumenta Chaloub. Para este, haveria uma engenhosidade dos higienistas brasileiros em produzir uma política de saúde pública racializada, posição contra a qual Maio desenvolve uma série de argumentos históricos, teóricos e estatísticos.

Simone Monteiro, por sua vez, procura definir teoricamente linhas de interpretação para as relações entre os conceitos de raça e etnia e a vulnerabilidade às doenças, focando uma articulação de grande densidade teórica e alcance político. Essa abordagem a permitiu considerar com isenção os esforços para a criação de um novo campo de pesquisa, denominado saúde da população negra. Por fim, a autora interroga sobre as possibilidades de formulação de 
políticas públicas racializadas no Brasil.

Em "Raça, etnicidade e saúde reprodutiva: o caso afro-latinoamericano", Livio Sansone nos convida para uma viagem etnográficocomprometida em direção a quatro contextos nacionais, em que a imbricação entre raça-etnicidade, sexualidade e gênero parece incidir, estruturando vulnerabilidades e desigualdades. Esses contextos são o Brasil, o México, a Nicarágua e a Colômbia. Com riqueza de detalhes e sensibilidade aguçada, o autor nos transporta para esses mundos racializados e sexualizados, nos quais os jovens estão nos centro das novas políticas do corpo e da identidade. O treinado olhar de Sansone chama a atenção para a maneira como a exposição dessas regiões tão diferentes à globalização produziu situações de fragilidade, mas também possibilidades de resposta.

A segunda parte do livro, "Etnicidade e saúde", aprofunda ainda mais o viés teórico e crítico que começamos a vislumbrar na parte anterior. $\mathrm{O}$ abrangente artigo de José Carlos dos Anjos apóia-se em sólida compreensão teórica do que ele chama de "perspectiva historicista nominalista" de extração focaultiana e no que está denominado em seu texto como "hermenêutica das diferenças culturais" (p. 97). A mobilização de um corpo teórico tão cerradamente urdido se presta à consideração política das representações sobre raça, corpo, doença e saúde que têm profundas implicações no campo das políticas públicas. Graças à sua abordagem, o autor pode demonstrar como os corpos foram sendo racializados no processo histórico brasileiro - ou seja, as raças não caíram do céu, nem são objetivamente reais, mas foram produzidas historicamente em ambientes politizados. Assim, o autor coloca com clareza: "não se diria que os negros são vítimas da ausência de políticas de saúde consistentes, mas que o modo como se (não) montam políticas de saúde é o constitutivo do ser do negro no Brasil" (p. 104).

Peter Fry, com a desenvoltura e brilho que o notabilizaram, vai na direção contrária, expressando seus temores de uma "birracializacão" do Brasil. "Há um movimento muito forte no Brasil para impor uma taxonomia racial bipolar" (p. 127). O autor discute medidas governamentais e o esforço da agência social afrodescendente para clarificar, identificar e definir como alvos de políticas públicas setores populacionais definidos de modo discreto como negros. A partir daí, questiona como seria possível definir quem é negro, o que oferece um contraste notável, muito estimulante para o leitor, com o texto anterior. Por fim, o autor conclui que as políticas racializadas não vão ao encontro do que existe 
objetivamente - as raças - mas as produzem efetivamente, com resultados eventualmente deletérios, antagônicos às intenções originárias dos atores sociais que as "inventaram".

A antropóloga colombiana Mara Viveiros Vigoya comenta o artigo de José Carlos dos Anjos de uma perspectiva privilegiada, matizada por sua própria experiência de pesquisa sobre representações para a sexualidade negra, vista como "indomada" ou "desenfreada". Coloca importantes questões para o próprio movimento negro latino-americano, ao chamar a atenção para as armadilhas da estereotipia e da fixação do negro como elemento pertencente a passados imaginários / imaginados.

Um dos aspectos mais interessantes do livro se refere à articulação que faz entre o campo dos estudos raciais, com sua agenda própria, e o dos estudos étnicos, ou voltados para os grupos indígenas brasileiros. A originalidade desse recorte se alia a sua profunda importância política e teórica, na medida em que as distintas experiências, acadêmicas e de engajamento, porventura permitem uma iluminação das problemáticas respectivas. Nesse sentido, a terceira parte da coletânea, "Saúde reprodutiva e população indígena" nos apresenta um conjunto de artigos muito bem fundamentados empiricamente, e com um olhar claro e determinado, peculiar à tradição dos estudos indígenas brasileiros, para os desafios das relações entre nacionais e índios, no que toca, em particular, à saúde reprodutiva. Aliás, se nos outros artigos as questões de gênero e sexualidade pareceram ganhar destaque, nesta parte a problemática da saúde e dos direitos reprodutivos se colocam no primeiro plano.

$\mathrm{O}$ artigo de Coimbra e Garnelo foca questões de saúde reprodutiva para a mulher indígena, definindo três temas principais: 1) a interface entre dinâmica demográfica e saúde reprodutiva, sobretudo no que tange à fecundidade; 2) perfil epidemiológico relacionado ao campo da saúde reprodutiva; 3 ) fatores socioculturais relacionados à saúde reprodutiva, com ênfase na interface entre antropologia da saúde e serviços de saúde.

A inserção dos direitos reprodutivos no campo mais ampliado dos direitos de cidadania, do ponto de vista da cultura e da luta política dos povos indígenas da América, é o ponto de partida da análise de Beth Conklin, editora do Medical Anthropological Quarterly. Para a autora, as visões nativas dos povos indígenas americanos sobre corpo, saúde e doença, por serem mais holísticas e relacionais, permitem uma vinculacão direta da saúde reprodutiva a noções mais abrangentes de direitos humanos e de cidadania, do que as concepções ocidentais. A chave 
de seu artigo é, desse modo, a problemática dos direitos e do protagonismo das mulheres indígenas, que em diferentes instâncias internacionais têm forçado a ampliação das pautas e sensibilidades de agências multilaterais e governos para as suas demandas, produzindo uma concomitante reversão epistemológica sobre nossas próprias noções.

Renato Athias, em "Corpo, fertilidade e reprodução entre os Pankararu: perspectivas e alcances", lança mão de sua vasta experiência de pesquisa com esse povo indígena e nos apresenta, com grande acuidade e consistência, diversos aspectos da vida sexual, mitológica e de gênero dos Pankararu, passado do namoro à gravidez, de práticas terapêuticas à sexualidade.

Por fim, Jean Esther Langdon, ao comentar o artigo de Athias, faz um balanço significativo da pesquisa antropológica nesse campo, ressaltando os déficits entre as promessas enunciadas em nossa avançada constituição e as práticas efetivas de atenção aos povos indígenas.

Na quarta e última parte do livro, "Saúde reprodutiva e população negra", encontramos o maior número de artigos, muitos dos quais mantêm a perspectiva encontrada nos artigos anteriores - a conciliação entre preocupações analíticas e a formulação de políticas. O primeiro texto, de André Junqueira Caetano, discute, a partir de sólido conhecimento das fontes "uma das maiores transformações sociais ocorridas" (p. 9) no Brasil nos últimos 40 anos: a queda da fecundidade brasileira. Caetano explora as relações desse fato com a realidade das mulheres pobres e, dentre estas, as negras, com atenção deliberada para a problemática da esterilização. Ao comentar o artigo de Caetano, Francisco Inácio Bastos salienta a complexidade dos resultados da análise acurada de Caetano, salientando a multicausalidade para a esterilização de mulheres negras. Ainda assim, Bastos conclui: "A raça é o batismo de fogo das nossas ciências sociais e uma dimensão inescapável da trajetória reprodutiva das brasileiras" (p. 255).

A equipe de trabalho, coordenada pelo sociólogo Fernando Urrea Giraldo, no CIDSE da Univalle, Colômbia, enriquece a coletânea com extenso e abrangente artigo que nos faz conhecer um pouco a realidade das relações raciais na Colômbia, de um modo geral, e em Cali em particular. Mais especificamente, o texto nos coloca diante da experiência social de raça, gênero e sexualidade entre jovens das camadas populares da referida cidade, não sem antes uma breve caracterização sócio-demográfica sobre a diversidade racial colombiana ${ }^{2}$. 
Fátima Oliveira optou por apresentarmos um panorama da saúde da população negra, ela que é uma das principais formuladoras desse novo campo de pesquisas e tem atuação engajada. Destaca, assim, diferenciais de morbidade e mortalidade precoce, demonstrando, dentre outras coisas, como a mortalidade proporcional por faixa etária é superior para os negros em relação aos brancos. Em seguida, elenca doenças que incidem desproporcionalmente, ou com maior gravidade, entre a população negra: diabetes mellitus tipo II, hipertensão arterial, síndrome hipertensiva na gravidez, miomas uterinos, anemia falciforme. A autora, médica e ativista do feminismo e do movimento negro, conclui com um apelo urgente à elaboração de um Plano Nacional de Atenção à Saúde da População Negra.

Em "Políticas públicas e desigualdade racial: do dilema à ação", Monica Grin procura produzir uma reflexão sobre o tipo de avaliação que segmentos do movimento social elaboram sobre políticas públicas. A autora procura levar em consideração a característica sui generis do sistema de relações raciais brasileiras. Em diapasão semelhante ao de Fry, a autora enumera algumas ações do governo que levam a raça em consideração. Por fim, identifica um paradoxo: como combater as incontornáveis desigualdades raciais brasileiras sem promover uma "violação" da "estrutura moral e afetiva" (p. 337) entre sujeitos sociais racializados no Brasil, mesmerizados pela ideologia da harmonia racial?

De maneira excepcional e muito feliz, o livro consegue captar ao mesmo tempo grandes temas gerais que perpassam o debate sobre as raças e o racismo no Brasil, como não perde de vista as sutilezas próprias a cada região específica de investigação e intervenção focalizadas. Os autores, especialistas destacados em suas áreas, parecem convergir em muitos pontos: por exemplo, sobre a urgência de reconhecermos e enfrentarmos as desigualdades étnicas e raciais no Brasil e na América Latina. Mas divergem em outros: o mais saliente, talvez, se refira ao dilema enunciado por tantos, de modo mais ou menos explícito. Como enfrentar o racismo e as desigualdades sem reificar as raças? $\mathrm{Ou}$ precisamos de uma política de identidade racial para dar cabo do racismo? Essas parecem ser questões que se alastram como fogo na grama seca por todo o Brasil atualmente. A história nos mostrará as melhores respostas. 


\section{NOTAS}

${ }^{1}$ Antropólogo, doutor em Ciências Sociais. Diretor do Centro de Estudos Afro-Brasileiros da Universidade Candido Mendes. E-mail: opinho@ candidomendes.edu.br.

${ }^{2}$ Para informações mais detalhadas sobre as relações raciais colombianas, ver o número especial dedicado ao tema da Revista Estudos Afro-Asiáticos, ano 25, jan. abr. 2003. Lá podem ser encontrados diversos artigos sobre cultura, política e demografia das populações negras colombianas. 